\title{
Empirične paremiološke raziskave tipov ekvivalentnosti in suprasemantičnih razlik v slovenščini in slovaščini
}

\author{
Peter Ďurčo, Matej Meterc \\ Univerzita sv. Cyrila a Metoda v Trnave, Filozofická fakulta, Námestie J. Herdu č. 2, \\ SK-917 01 Trnava; Univerzita Komenského v Bratislave, Pedagogická fakulta, \\ Račianska 59, SK-81334 Bratislava,durco@vronk.net; \\ Jesenice,matej.meterc@gmail.com
}

\begin{abstract}
Slovensko in slovaško paremiologijo primerjamo s pomočjo Ďurčeve tipologije frazeoloških ustreznic in medjezikovnih suprasemantičnih razlik. Osnova za primerjavo je paremiološki minimum petdesetih najbolj poznanih slovenskih pregovorov, ki je nastal s široko demografsko raziskavo. Pogostnost slovenskih enot in njihovih slovaških ustreznic smo preverili v jezikovnih korpusih. Razmišljamo, kako so tipi suprasemantičnih razlik medsebojno povezani.
\end{abstract}

Slovene and Slovak paremiology are compared with the help of Durčo's typology of phraseological equivalents and interlingual suprasemantic differences. The basis for the comparison is the paremiological minimum of the most well-known Slovene proverbs, which was determined with a demographic survey. The frequency of the Slovene units and their Slovak equivalents were checked in language corpora. The study also explores how different types of suprasemantic differences are interconnected.

Ključne besede: paremiološki minimum, empirična paremiologija, pregovori, frazeološke ustreznice, suprasemantika

Key words: paremiological minimum, empirical paremiology, proverbs, phraseological equivalents, suprasemantics

\section{Ekvivalentnost in empirične raziskave}

Prednost nove tipologije frazeoloških ustreznic (Ďurčo 2012: 93) je v primerjavi z dosedanjimi tipologijami (Korhonen 2007: 575, Hallsteinsdótirr-Farø 2010: 126) v tem, da je zasnovana na modelu osnovnih logičnih odnosov oziroma 
ne izhaja le iz opazovanja naključno izbranih primerov. Ta model je na ravni leksikologije uspešno apliciral Dolník (1987: 129-131). Osnovne tipe ekvivalentnosti, ki jih bomo predstavili v nadaljevanju, lahko proučujemo v okviru enega jezika ali pa jih uporabimo za medjezikovno primerjavo, kot je to v našem primeru v okviru slovaške in slovenske frazeologije. Tem tipom je Ďurčo dodal nabor tipov suprasemantičnih razlik. Tipologijo bomo soočili s podatki, ki smo jih pridobili s široko demografsko raziskavo poznanosti slovenskih paremij ${ }^{1}$ s spletnim vprašalnikom na naslovu www.vprasalnik.tisina.net, ki je bil predstavljen na konferenci Europhras v Mariboru (Meterc 2013, v tisku). Izhodiščni korpus paremij za vprašalnik je bil narejen z upoštevanjem vrste metodoloških postavk (Grzybek, Baur, Chlosta 1996: 164-165). Izbira virov zanj ustreza primerljivi raziskavi v slovaščini.

Durčeva raziskava (2002: 51-52) je zaradi večjega števila uporabnih virov zajela več (2834) enot kot slovenska, vprašanja pa so bila identična. Anketo je v celoti izpolnilo 42 oseb. V slovenski raziskavi smo 918 paremij izpisali iz Slovarja slovenskega knjižnega jezika in Frazeološkega slovarja v petih jezikih iz leta 1960. Kljub temu da je bila obdelava frazeološkega gradiva v obeh slovarjih deležna kritike (Suhadolnik 1961: 205, Kržišnik 1988: 143-144, Logar 2001: 147), smo se zanju odločili zaradi pomanjkanja drugih slovarskih virov. Zbirke, kakršna je Bojčeva (1987), uporabljamo le kot sekundarne vire. Kot sekundarni vir uporabljamo tudi edine sodobnejše terensko zbrane podatke iz raziskave Marije Makarovič (1975). Ta predstavlja pomembno sondo, kot poudarja Grzybek (2008: 24-25), ocenjujemo pa, da tudi precej omejeno, saj izhaja le iz stotih intuitivno izbranih enot. Ta zamejitev je verjetno zmanjšala razpon enot, ki so jih dodali nekateri izmed 64 anketirancev. Naš demografski vprašalnik je od 21. aprila do 13. oktobra 2012, ko smo podatke zamrznili za prvo različico minimuma, ocenilo 316 oseb. ${ }^{2}$ Paremije smo anketirancem prikazovali v celoti po metodološkem principu FTP (full text presentation). Za prikaz polovice enote po principu PTP (part text presentation) se nismo odločili glede na razprave o prednostih in pomankljivostih teh dveh in sorodnih pristopov (Grzybek, Chlosta 2008: 97-98). Vsako enoto je anketiranec ocenil Z enim izmed naslednjih odgovorov: 1. poznam in uporabljam, 2. poznam, a ne uporabljam, 3. ne poznam, a razumem, 4. ne poznam in ne razumem in 5. poznam varianto ( $\mathrm{z}$ vpisom variante). Za vprašalnik nismo izbrali nobenega izmed obstoječih spletnih orodij, temveč smo pripravili lastno orodje, ki je potrebam raziskave prilagojeno tako, da lahko rezultate razvrščamo s filtri po enem demografskem podatku ali po več podatkih o anketirancih (starost, spol, izobrazba, narečna skupina ob rojstvu ter narečna skupina sedanjega bivališča).

${ }^{1}$ Izhodiščni korpus za paremiološki minimum in optimum smo omejili na pregovore in reke. Ostale tipe paremij, npr. uganke, v raziskavo nismo vključili.

${ }^{2}$ Najstarejši anketiranec se je rodil leta 1933, najmlajši leta 2000. Prihajajo z vseh koncev Slovenije in tudi iz zamejstva ter drugod iz tujine. Zastopane so vse stopnje izobrazbe od prve do osme. 
Prikaz šestnajstih osnovnih tipov ekvivalence bo temeljil na paremiološkem minimumu petdesetih najbolj poznanih slovenskih paremij in na njihovih slovaških ustreznicah. ${ }^{3}$ Ideja minimuma, ki jo je prvi predstavil Permjakov (1988: 143, 1989: 92-93), ostaja ena izmed osrednjih tem sodobne frazeologije, saj teži $\mathrm{k}$ razmejitvi aktivnega in pasivnega frazeološkega fonda. Različni raziskovalci k njej pristopajo različno. Čermák (2003: 29-31) je tako minimum določil po pogostnosti enot v češkem korpusu, Grzybek in Chlosta (1996: 162-163) sta raziskala poznanost hrvaških in nemških paremij z anketiranjem, ruski frazeolog Mokijenko (2012: 83) pa zagovarja tezo o gibljivem območju minimuma. Wolfgang Mieder (1997: 406, 2004: 127-129) poudarja, da je kljub množici različnih pristopov seznam aktivno rabljenih pregovorov v posameznem jeziku smiseln cilj. Pogostnost tristotih najbolj znanih pregovorov določamo v korpusu FidaPLUS, pogostnost enakega števila slovaških enot pa v SNK (Slovenský národný korpus). Podatki o poznanosti in pogostnosti so ključni za raziskovanje suprasemantičnih razlik med frazeološkimi enotami, ki ga bomo približali v drugem delu razprave. Upoštevamo pomemben metodološki napotek sodobne frazeologije o poznanosti in pogostnosti kot dveh ločenih fenomenih s krožnim medsebojnim vplivanjem (Grzybek, Chlosta 2008: 96). Jedro gradiva za medjezikovno primerjavo sta izhodiščna korpusa za slovaški (Ďurčo 2002: 52) in slovenski (Meterc 2013: 363) paremiološki optimum. Paremiološki optimum je Ďurčeva metodološka nadgradnja minimuma, saj prikaže presečišče najbolj pogostih in najbolj poznanih enot (Ďrčo 2006: 17). Dodatno gradivo črpamo s portala Sprichwort-Plattform ter iz slovarja Krátky slovník slovenského jazyka (v nadaljevanju: KSSJ).

Opisali in prikazali bomo distribucijo tipov ekvivalentnosti med petdesetimi najbolj poznanimi slovenskimi enotami in njihovimi slovaškimi ustreznicami. Poleg pregleda osnovnih šestnajstih tipov medjezikovnih ustreznic in nekaterih tipov suprasemantičnih razlik, za katere smo podatke pridobili s pomočjo demografske in korpusne raziskave, želimo razmisliti, kakšne raziskave bi v prihodnosti lahko sistematično opisale preostale tipe suprasemantičnih razlik.

\section{Sistemskolingvistična ekvivalentnost}

Frazeološke enote s sistemskolingvističnega vidika vstopajo v naslednje binarne opozicije oblike in pomena: identitete (I), privativne (P), ekvipolentne (E) ali gradualne $(\mathrm{G})$ opozicije ter disjunkcije (D). Gradualno opozicijo smo izločili iz razmerij oblike in pomena ter jo vpeljali v suprasemantične odnose, saj gre ravno pri njih za mero intenzivnosti zaznamovanosti (Ďurčo 2012: 93). Razmerje med obliko in pomenom dveh frazeoloških enot se tako lahko pojavlja v naslednjih možnih kombinacijah:

${ }^{3}$ Za minimum bi lahko izbrali tudi večje število enot, urejenih glede na njihovo poznavanje pri govorcih. Seznam petdesetih enot se nam zdi dovolj obsežen za prikaz distribucije tipov ekvivalentnosti. 


$$
\begin{array}{llllllllllllllll}
\underline{\mathrm{FI}} & \underline{\mathrm{FI}} & \underline{\mathrm{FI}} & \underline{\mathrm{FI}} & \underline{\mathrm{FP}} & \underline{\mathrm{FP}} & \underline{\mathrm{FP}} & \underline{\mathrm{FP}} & \underline{\mathrm{FE}} & \underline{\mathrm{FE}} & \underline{\mathrm{FE}} & \underline{\mathrm{FE}} & \underline{\mathrm{FD}} & \underline{\mathrm{FD}} & \underline{\mathrm{FD}} & \underline{\mathrm{FD}} \\
\mathrm{SI} & \mathrm{SP} & \mathrm{SE} & \mathrm{SD} & \mathrm{SI} & \mathrm{SP} & \mathrm{SE} & \mathrm{SD} & \mathrm{SI} & \mathrm{SP} & \mathrm{SE} & \mathrm{SD} & \mathrm{SI} & \mathrm{SP} & \mathrm{SE} & \mathrm{SD}
\end{array}
$$

Na ravni oblike in pomena si pri nekaterih tipih stojijo nasproti enaki tipi opozicij, pri nekaterih bližnji, pri drugih pa nesorodni. Zato ločimo popolnoma simetrične, delno simetrične, delno asimetrične in asimetrične tipe. Podrobneje smo ta razmerja medjezikovne ekvivalence že opisali (Ďurčo 2012a: 93-94).

\subsection{Slovenski paremiološki minimum in sistemskolingvistična ekvivalentnost s slovaškimi enotami}

Na najvišjem mestu v slovenskem minimumu je enota Kdor išče, najde, ki jo pozna $99,7 \%$ anketirancev, na zadnjem pa enota Dobrota je sirota, ki jo pozna $98,4 \%{ }^{4}$ Večini enot iz slovenskega paremiološkega minimuma (36 enotam) smo našli po eno ustreznico, devetim dve, dvema tri in eni štiri ustreznice. Skupaj smo jih našli 68 . Med njimi jih je 12 iz nabora 50 najbolj poznanih slovaških enot, nadaljnjih 34 iz nabora 500 najbolj poznanih in 23 iz sekundarnih virov. $\mathrm{K}$ temu ne prištevamo dveh s frazemske strukturne ravni. ${ }^{5}$ Problem transformacij in njihove recepcije pri govorcih smo že obravnavali (Meterc 2012: 325).

\begin{tabular}{|l|l|l|l|l|l|l|l|l|}
\hline Enota paremiološkega minimuma & FISI & FPSI & FESI & FESP & FESD & FDSI & FDSP & FDSE \\
\hline 1. Kdor išče, najde. & 1 & & & & & & & \\
\hline 2. Počasi se daleč pride. & & & 1 & & & & & \\
\hline 3. Več glav več ve. & & & 1 & & & & \\
\hline 4. Kjer se prepirata dva, tretji dobiček ima. & & & 1 & & & & \\
\hline 5. Po toči zvoniti je prepozno. & & & & & 2 & & \\
\hline 6. Čas celi srčne rane. & & & & 1 & & & 1 & \\
\hline 7. Lepa beseda lepo mesto najde. & & & & & & & & 1 \\
\hline 8. Zarečenega kruha se največ poje. & & & & & & 1 & & \\
\hline 9. Klin se s klinom izbija. & & & 1 & & & & & \\
\hline 10. Denar je sveta vladar. & & & 1 & & & & & \\
\hline 11. Zrno do zrna pogača, kamen do kamna palača. & & & & & & 1 & & \\
\hline 12. Jabolko ne pade daleč od drevesa. & 1 & & & & & & 2 & \\
\hline 13. Za malo denarja malo muzike. & 1 & & & & & & \\
\hline
\end{tabular}

${ }^{4} 24$ anketirancev (7,6 \%) je navedlo Kdor išče, ta najde, kar je signal, da v rabi prevladuje varianta z zaimkom.

${ }^{5}$ Gre za frazema kut železo zahorúca/kým je horúce ter príst' k niečomu ako slepálslepé kura $k$ zrnu iz KSSJ. 


\begin{tabular}{|c|c|c|c|c|c|c|c|c|}
\hline 14. Pes, ki laja, ne grize. & 1 & & & & & & & \\
\hline 15. Nobena juha se ne poje tako vroča, kot se skuha. & & 1 & & & & & & \\
\hline 16. Kdor čaka, dočaka. & $1^{*}$ & & & & & 1 & & \\
\hline 17. Rana ura - zlata ura. & $1^{*}$ & & & & & $3^{*}$ & & \\
\hline 18. Kdor drugim jamo koplje, sam vanjo pade. & & 1 & & & & & & \\
\hline 19. Iz te moke ne bo kruha. & & & $1^{*}$ & & & & & \\
\hline 20. Kar se Janezek nauči, to Janez zna. & & & $1^{*}$ & & & & & \\
\hline 21. Kdor se zadnji smeje, se najslajše. & & & 1 & & & & & \\
\hline 22. Kar danes lahko storiš, ne odlašaj na jutri. & 1 & & & & & & & \\
\hline 23. Prijatelja spoznaš v nesreči. & 1 & & & & & & & \\
\hline 24. Boljši je vrabec v roki kakor golob na strehi. & & & 1 & & & & & \\
\hline 25. Enkrat ni nobenkrat. & & & $1^{*}$ & & & & & \\
\hline 26. Vsi za enega, eden za vse. & 1 & & & & & & & \\
\hline 27. Najprej štalica, potem kravica. & & & & & & 11 & & \\
\hline 28. Vaja dela mojstra. & $1^{*}$ & & & & & $1^{*}$ & & \\
\hline 29. Bolje pozno kot nikoli. & 1 & & & & & & & \\
\hline 30. Ljubo doma, kdor ga ima. & & & & & & & & 1 \\
\hline 31. Pri enem ušesu mu gre noter, pri drugem pa ven. & & & 1 & & & & & \\
\hline 32. Ni vse zlato, kar se sveti. & 1 & & & & & & & \\
\hline 33. Kdor z malim ni zadovoljen, velikega vreden ni. & & & & & & & $1^{*}$ & \\
\hline 34. Ne hvali dneva pred večerom. & 1 & & 1 & & & & & \\
\hline 35, Tudi slepa kura včasih zrno najde. & & & 1 & & & & & \\
\hline 36. Brez muje se še čevelj ne obuje. & & & & & & 1 & & \\
\hline 37. Saj nisva skupaj krav pasla. & & & 1 & & & & & \\
\hline 38. Kuj železo, dokler je vroče. & $1^{*}$ & & & & & & & \\
\hline 39. V tretje gre rado. & & & 1 & & & & & \\
\hline 40. Kdor prej pride, prej melje. & 1 & & 1 & & & & & \\
\hline 41. Pametnejši odneha. & & & 1 & & & & & \\
\hline 42. Vse ob svojem času. & & & & & & 1 & & \\
\hline 43. Konec dober, vse dobro. & 1 & & & & & & & \\
\hline 44. Kdor visoko leta, nizko pade. & & $1^{*}$ & 1 & & & & & \\
\hline 45. Pustimo času čas. & & & & & & 11 & & \\
\hline 46. Laž ima kratke noge. & 1 & & & & & & & \\
\hline
\end{tabular}




\begin{tabular}{|l|l|l|l|l|l|l|l|l|}
\hline 47. Kadar mačke ni doma, miši plešejo. & & & 2 & & $1^{*}$ & & & \\
\hline 48. Ura teče, nič ne reče. & & & 1 & & & & & \\
\hline 49. Hiti počasi. & 1 & & & & & 1 & & \\
\hline 50. Dobrota je sirota. & & & & & & 11 & & \\
\hline
\end{tabular}

Legenda: Podčrtanim enotam smo našli ustreznice v slovaškem minimumu 50 najbolj poznanih paremij. Števila v poševnem tisku so ustreznice, najdene v sekundarnih virih izven nabora 500 najbolj poznanih slovaških paremij. Z zvezdico označujemo slovaške ustreznice z opazno diasistemsko razliko.

\subsection{Posamezni tipi ekvivalentosti}

Z dosedanjimi raziskavami med slovaškim, ruskim in nemškim (Ďurčo 2012: 93-94) ter med slovaškim in slovenskim gradivom smo odkrili primere, ki so potrdili 14 izmed 16 teoretično možnih tipov. Iz primerjave slovenskega in slovaškega paremiološkega gradiva lahko približno ocenimo, kateri tipi so bolj pogosti in kateri manj. Bolj natančno sliko bo prinesla primerjava slovenskega paremiološkega optimuma s slovaškim. Ta primerjava bo omogočila ugotavljanje distribucije tipov po intervalih glede na pogostnost in poznavanje paremij hkrati.

V okviru slovenskega minimuma in njegovih slovaških ustreznic smo našli polovico tipov ( 8 od 16). Med pogosteje zastopanimi tipi je največ leksikalno-transpozicijske variantnosti (21), sledita idionimija in sinonimija (obe po 18), ekstenzivna in intenzivna hipernimija (4), formalna variantnost (3) ter ekvipolentna sinonimija (2), z enim primerom pa sta zastopani tudi specifikacija in neprava paronimija.

\subsubsection{Idionimija (FI:SI)}

Idionimija je binarna opozicija formalne in semantične identičnosti frazeoloških enot. Obravnava jo tudi Čermák (1983: 210). Primer zanjo sta enoti Pes, ki laja, ne grize in Pes, ktorý breše, nehryzie.

\subsubsection{Formalna variabilnost (FP:SI)}

Formalna privativna opozicija in semantična identiteta pomenita, da se pomensko enaki enoti razlikujeta po obliki sestavin. Primera za to sta enoti Kdor visoko leta, nizko pade in Kto vysoko lieta, nizko padá. V slovaški paremiji sta oba glagola nedovršna. 


\subsubsection{Leksikalno-transpozicijska variabilnost (FE:SI)}

Pri leksikalno-transpozicijski variabilnosti gre za formalno ekvipolentno opozicijo in semantično identiteto. Paremiji Kdor se zadnji smeje, se najslajše smeje in Kto sa smeje naposledy, ten sa smeje najlepšie imata $\mathrm{z}$ vidika oblike razen skupnih sestavin tudi različne, pomensko pa sta identični.

\subsubsection{Formalno-semantična specifikacija (FE:SP)}

Odnos formalne ekvipolentne in semantične privativne opozicije pomeni, da imata enoti razen skupnih tudi različne sestavine, pomensko pa se razlikujeta le v eni sestavini. Slovenska paremija Čas celi srčne rane v primerjavi s slovaško Čas všetko zahoji (dobesedni prevod: čas vse zaceli) izraža ožji pomen.

\subsubsection{Prava medjezikovna sinonimija (FD:SI)}

Pravi sopomenski frazeološki enoti imata različno strukturo sestavin, pomensko pa sta identični. Primer sta slovenska enota Brez muje se še čevelj ne obuje in slovaška enota Bez práce nie sú koláče.

\subsubsection{Ekvipolentna sinonimija (FD:SE)}

Formalna disjunkcija in semantična ekvipolentna opozicija tvorita ekvipolentno sinonimijo. Taka sinonima sta Lepa beseda lepo mesto najde in Ako sa do hory volá, tak sa z hory ozýva (dobesedni prevod: kakor do gore kličeš, tako z nje odmeva). Po obliki se popolnoma razlikujeta, imata skupne semantične sestavine (sorazmernost $\mathrm{v}$ človeških odnosih), poleg njih pa tudi razlikovalne (pri slovenski gre za govorno dejanje in poudarjanje vljudnosti).

\subsubsection{Ekstenzivna ali intenzivna hipernimija (FD:SP)}

Formalna disjunkcija in semantična privativna opozicija nastopata pri različno motiviranih frazeoloških enotah, ki sta v razmerju nadpomenke in podpomenke. Obliki enot tega tipa se popolnoma razlikujeta, pomen pa le po eni sestavini. Slovenska enota Jabolko ne pade daleč od drevesa ima v odnosu do ustreznic Aká matka, taká Katka, taká celá jej čeliadka in Aký otec, taký syn, aké drevo, taký klin širši pomen, ker ne določa spola. 
2.2.8 Neprava medjezikovna paronimija (FE:SD)

Za ta tip je značilen odnos formalne ekvipolentne opozicije in semantične disjunkcije. Frazeološki enoti imata poleg enakih formalnih sestavin tudi drugačne, na semantični ravni pa nimata nič skupnega. Primer je odnos med slovenskim pregovorom Ko mačke ni doma, miši plešejo in slovaškim Nemajú myši každý deň bál. V zbirki Zatureckéga (1896: 207) je slovaška enota navedena v poglavju »nestalnost sreče«. Je zastarela enota in po pomenu blizu slovenski Ni vsak dan nedelja/praznik.

\subsubsection{Ekstenzivna divergenca (FI:SP)}

Binarno opozicijo formalne identitete in semantične privativne opozicije dveh frazeoloških enot lahko označimo kot medjezikovno ekstenzivno divergenco. Med prvimi petdesetimi najbolj poznanimi slovenskimi paremijami in njihovimi slovaškimi ustreznicami na ta tip (in na preostale tipe, opisane v nadaljevanju) nismo naleteli. Polisemantična enota Kakor ti meni, tako jaz tebi ima v slovaščini monosemantično ustreznico Ako ty mne, tak ja tebe. Ta izraža le negativno, medtem ko slovenska lahko izraža tudi pozitivno vrednotenje.

\subsubsection{Intenzivna divergenca (FI:SE)}

Pri tem tipu gre za binarno opozicijo formalne identitete in ekvipolentne semantične inkluzije. Formalno identični enoti se delno razlikujeta v sestavi in naravi semantičnih sestavin. Slovaški pregovor Potkany opúšt’ajú lod' opisuje strahopetnost ljudi v kritični situaciji in opustitev skupnega prizadevanja za rešitev, slovenski idionim Podgane zapuščajo ladjo pa pomeni tudi, da gre za strahopetno dejanje oseb, ki so odgovorne za nastalo situacijo.

\subsubsection{Medjezikovna homonimija (FI:SD)}

Binarno opozicijo formalne identitete in semantične disjunkcije označujemo kot medjezikovno homonimijo. Razlikujemo pravo in nepravo medjezikovno homonimijo. Nepravi medjezikovni homonim je jezikovna vzporednica, ki je dobesedni prevod izhodiščne enote in ji v drugem jeziku lahko pripišemo zgolj potencialni pomen v konkretni govorni situaciji. Dobesedni prevod paremije Ked' neprší, aspoň kvapká v slovenščino Če ne dežuje, vsaj kaplja opisuje vreme, slovaški pregovor pa poudarja pomen skromnosti. Pravi homonimi so ustaljene jezikovne vzporednice z drugačnim pomenom. Primer poznamo iz primerjave nemških in slovaških paremij (Ďurčo 2012a: 97). Za primer homonimov v slovenščini lahko navedemo frazem (biti) osje gnezdo in osje gnezdo kot oznako za vrsto peciva. 


\subsubsection{Formalno-semantična mutacija (FE:SE)}

Odnos formalne in semantične ekvipolentne opozicije pomeni, da imata dve frazeološki enoti razen skupnih formalnih sestavin tudi drugačne sestavine, prav tako pa je s semantičnimi sestavinami. Pomen slovaške enote Ked' je somárovi dobre, ide na l'ad tancovat' (Ko je oslu dobro, gre na led plesat) je po KSSJ: človek si pogosto sam povzroča težave. Podobno situacijo opisuje slovenska enota Osel gre samo enkrat na led. To semantično jedro je pri slovenski enoti dopolnjeno s sestavino enkratnega dejanja, pri slovaški pa s trditvijo, da človek nepremišljeno ravna v situaciji, ko mu gre dobro.

\subsubsection{Prava paronimija (FP:SD)}

Binarni odnos formalne privativne opozicije in semantične disjunkcije pomeni pravo paronimijo. Dve frazeološki enoti se formalno razlikujeta le po eni sestavini, s semantičnega vidika pa nimata nič skupnega. Odnos prave paronimije je med slovensko enoto Naj ne ve tvoja levica, kaj dela desnica in slovaško Pravica nevie, čo robí l’avica. Prva enota izraža napotek, naj se človek ne hvali z dobrimi deli, kar potrjujejo tudi primeri, najdeni v korpusu FidaPLUS. Druga enota opisuje neskladno delo. Primeru smo se posvetili v članku o antonimiji (Meterc 2013: 367).

\subsubsection{Idiosinkrazija (FD:SD)}

Idiosinkrazija je nasprotje idionimije, saj se disjunkcija pojavlja tako na formalni kakor tudi na semantični ravni. Ko v jeziku obstaja frazeološki izraz, ki v drugem nima frazeološke ustreznice, ga lahko interpretiramo le eksplicitno. Tak je slovenski pregovor $\breve{C}$ greš na Dunaj, pusti trebuh zunaj. Pogosto gre za enote s sestavinami, ki so vezane na specifična geografska okolja in zgodovinske okoliščine. Slovaški pregovor Zaživa v Bystrici, po smrti v nebi izraža sloves Banske Bystrice, ki je bila nekoč bogato rudarsko mesto.

\subsubsection{Formalno-semantična modifikacija (FP:SP)}

Binarni odnos formalne in semantične privativne opozicije je situacija, ko se enoti formalno in semantično razlikujeta le po eni specifični sestavini. Po Dolníku (1987: 132) gre v okviru leksikalnih enot za modifikacijo, ki privede npr. do kategorije deminutivnosti. Z večanjem števila raziskav se bo nabor primerov še povečeval. Zaradi ogromnega nabora nestavčnih frazemov in možnosti uporabe tipologije znotraj enega jezika, ni izključeno, da bosta v prihodnosti potrjena tudi ta in naslednji tip. 


\subsubsection{Formalno-semantična derivacija (FP:SE)}

Primer, pri katerem bi šlo za kombinacijo formalne privativne ter semantične ekvipolentne opozicije, bi označili kot formalno-semantično derivacijo. Enoti bi se formalno razlikovali le v eni sestavini, semantično pa bi poleg skupnih imeli tudi različne sestavine. Derivacijo na ravni leksikologije opisuje Dolník (1987: 132) pri tvorbi glagolov, samostalnikov in pridevnikov s predponskimi obrazili.

\section{Suprasemantična ekvivalentnost}

Primerjalno raziskovanje frazeologije je treba razširiti tudi na t. i. suprasemantično ekvivalentnost. Pri raziskovanju ekvivalentnosti enot v diasistemu jezika ugotavljamo mero ekvivalentnosti v aktualni rabi, pri čemer uveljavljamo princip gradualne opozicije. Gre za razlike v intenzivnosti zaznamovanosti. Na osnovi raziskav, ki smo jih izvedli, ${ }^{6}$ lahko največ povemo o prvih dveh tipih suprasemantičnih razlik. Podatki o poznanosti in pogostnosti enot nam do določene mere pomagajo tudi pri ostalih tipih diasistemskih razlik. Razmisliti želimo, kakšne raziskave bi nam lahko pomagale pri bolj točnem določanju.

\subsection{Diahrona razlika}

Pozorni smo na obstoj enot v sodobnem jeziku. Včasih je ena izmed ustreznic del aktivne frazeologije, druga pa zastarela in se $\mathrm{v}$ rabi pojavlja redko ali zanemarljivo malo. Takšna razlika je po naši oceni med enotama Ranná hodina, zlatá hodina in Rana ura - zlata ura. Slovaška enota je zastarela, najdemo jo v delu Zátureckega (1896: 164). Izsledki vprašalnika kažejo, da slovensko enoto pozna in uporablja 80,7 \% govorcev, pozna, ampak ne uporablja $18 \%$, eden $(0,3 \%)$ pa je navedel variantno obliko.

\subsection{Diafrekvenčna razlika}

Frazeološki ustreznici se lahko bistveno razlikujeta po pogostnosti v rabi. To razliko lahko ugotovimo s primerjavo stanja v jezikovnih korpusih. Primer

\footnotetext{
${ }^{6}$ Podatke navajamo glede na trenutni nabor odgovorov anketirancev (2. 6. 2013), saj se ta že razlikuje od stanja, $v$ katerem je bila baza podatkov zamrznjena za prvo različico slovenskega paremiološkega minimuma (13. 10. 2012). Poleg tega upoštevamo odgovore vseh anketirancev - tudi tistih, ki vprašalnika niso izpolnili v celoti -, saj nam naključni prikaz enot $\mathrm{v}$ času izpolnjevanja ankete zagotavlja uravnoteženo distribucijo odgovorov na frazeološko enoto. 2. 6. 2013 je vprašalnik v celoti rešilo 369 anketirancev, enote pa so bile v povprečju deležne od 570 do 580 odgovorov. Upoštevamo tudi odgovore na zaključna vprašanja vprašalnika, v katerih smo anketirancem dali možnost, da naštejejo enote, ki jih po njihovi oceni ni bilo v jedru vprašalnika.
} 
sta paremiji Kakor se v gozd kliče, tako odmeva (Bojc 1987: 339) in Ako sa do hory volá, tak sa z hory ozýva. O dokaj veliki pogostnosti slovaške enote priča 58 pojavitev v korpusu SNK s pogojem [lemma $=»$ volat' «][]\{0,5\}[lem$\left.m a=» o z y ́ v a t^{\dagger} \ll\right]$. Slovenske enote v korpusu FidaPLUS nismo našli. Dvanajst slovaških enot, ki smo jih našli v sekundarnih virih, se diafrekventno razlikuje v primerjavi z ustreznicami iz slovenskega minimuma, saj smo jih v korpusu SNK našli v zanemarljivem številu ali pa jih sploh nismo našli.

\subsection{Diaintegrativna razlika}

Ekvivalentnost frazeoloških enot primerjamo z vidika njihovega izvora. Predmet proučevanja je dihotomija domače : prevzeto. Zanima nas stanje, ko govorci čutijo, da integracija enote v jezik ni potekla. Enoto Len raz je ako nikdy smo v korpusu SNK našli le enkrat kot prevod ob nemškem pregovoru. Njeno slovensko ustreznico Enkrat ni nobenkrat pozna in uporablja 78,2 \% anketirancev. Z 49 pojavitvami po pogoju enkrat//nobenkrat v FidaPLUS gre tudi za diafrekvenčno razliko.

\subsection{Diamedialna razlika}

To razliko določimo z upoštevanjem ekvivalentnosti z vidika prevladovanja ustreznic v govoru ali v pisni rabi. Primer diamedialne razlike sta enoti Ista pašta in Jeden za osemnást', druhý bez dvoch za dvadsat', saj se slovenska enota večinoma pojavlja v govoru, slovaška pa je pogosta tudi v pisni rabi. Enoti se poleg tega razlikujeta tudi dianormativno, ker je slovaška knjižna, slovenska pa pogovorna. $\mathrm{V}$ izhodiščnem korpusu je ni bilo, med dodatnimi odgovori se pojavi dvakrat, v korpusu FidaPLUS (iskalni pogoj \#1isti_pašt*) pa le petkrat. Diamedialna razlika je bila ob določanju nemškega paremiološkega optimuma (Ďurčo 2006: 15-16) močno opazna pri 18 enotah, ki so splošno znane (od $86,07 \%$ do $100 \%$ anketirancem), hkrati pa kažejo nizko pogostnost (0 do 14 pojavitev) v jezikovnem korpusu. Znotrajjezikovno diamedialno razliko bomo lahko ugotavljali na podlagi primerjave lestvice najbolj rabljenih slovenskih pregovorov (razvrščenih glede na delež odgovorov št. 1) z lestvico enot, urejeno glede na pogostnost v korpusu. Pri enotah z občutnim razhajanjem bomo lahko sklepali, da enota prevladuje v govoru.

\subsection{Diastratična razlika}

Pri določanju diastratične razlike opazujemo socialno pogojene razlike in razmerje enot do sociolekta. Enota Ista pašta bi lahko ustrezala tem merilom. Pogrešamo širše raziskave zvrstnosti slovenskih frazemov. Lahko bi ugotovili, 
kako je povezana z drugimi diasistemskimi razlikami. Domnevamo, da se odraža na diafrekvenčni in diamedialni razliki.

\subsection{Diatekstovna razlika}

Pomembno je prevladovanje primerjanih enot v različnih tipih besedil. Paremija Duh je voljan, ali meso je slabo je v slovenščini heterosituativna, kar je sicer ena glavnih značilnosti pregovorov (Mieder 2004: 132). Ne uporablja se izključno v svetopisemskem kontekstu kot enota Duch je sice ochotný, ale telo je slabé v slovaščini. To potrjuje stanje v korpusih obeh jezikov. Zdi se razumljivo, da je diatekstovna razlika povezana $z$ diafrekvenčno razliko, saj omejevanje rabe paremije na določen tip besedila pomeni tudi manjšo pogostnost.

\subsection{Diatopična razlika}

Pri tej razliki raziskujemo dihotomijo vsenarodno : regionalno in ugotavljamo mero teritorialne razširjenosti ali pa narečnosti primerjanih frazeoloških enot. Take razlike sta na primeru angleških paremij v Kanadi in Združenih državah Amerike opisala Grzybek in Chlosta (1995: 76). Splošno razširjenemu slovaškemu pregovoru Nemému diet'at'u ani vlastná mat' nerozumie odgovarja pregovor Mati molčečemu detetu niš ne veruje v belokranjskem narečju (Bisernice iz belokranjskega narodnega zaklada). Enota se med dodatnimi odgovori v vprašalniku ne pojavlja. ${ }^{7}$ V korpusu ga s pogojema »lastna_mati_ne« ter »\#1nem_\#1otrok« nismo našli. Diatopična razlika se zagotovo odraža v diafrekvenčni razliki, zaznavanje tega vpliva pa bi bilo nedvomno odvisno od strukture besedil v jezikovnem korpusu. Ker nam spletno orodje vprašalnika o poznavanju slovenskih paremij omogoča vključevati različne demografske filtre in med njimi tudi narečno skupino, $v$ kateri je anketiranec odraščal in skupino, v kateri živi v času reševanja, bo v prihodnosti vsaj do določene mere možno raziskati znotrajjezikovno diatopično razliko.

\subsection{Diafazična razlika}

Diafazična razlika je lahko razlika v ekspresivnosti enot (diaevaluativna) ali razlika v njihovem stilističnem uveljavljanju (diasituativna).

${ }^{7} \mathrm{~V}$ odgovorih anketirancev se enote $\mathrm{z}$ narečnimi prvinami pojavljajo v manjšem številu, kot bi to glede na pestro razvejanost slovenskih narečij lahko pričakovali. Temu vprašanju se nameravamo posvetiti v ločenem članku. 


\subsubsection{Diaevaluativna razlika}

Diaevaluativna razlika je povezana $\mathrm{z}$ različno motivacijo enot, ki je lahko v enem jeziku bolj ekspresivna, v drugem pa manj. Pregovora Ne čohaj se, kjer te ne srbi in Nehas, čo t'a nepáli (Ne gasi, kar te ne peče) imata različen status na osi pejorativno - nevtralno. Ta leksikalna varianta pregovora Ne praskaj se, kjer te ne srbi je tudi edini pregovor v SSKJ s kvalifikatorjem nizko.

\subsubsection{Diasituativna razlika}

Raziskujemo lahko različno mero situacijske in funkcijske stilistične obarvanosti. Slovaška paremija Šuster drž sa svojho kopyta ima v slovenščini ustreznico Čevljar ostani pri svojem kopitu (Pavlica 1960: 50). Gre za očitno diahrono razliko, ki je razvidna tudi iz odgovorov v raziskavi. Pozna in uporablja jo le $8,2 \%$, pozna, a ne uporablja pa $25,6 \%$. V vseh dodanih variantah $(8,5 \%)$ so anketiranci zapisali enoto Le čevlje sodi naj Kopitar. Ta se od nje razlikuje s svojo citatnostjo, povezanostjo z leposlovjem ter biografskimi podatki Franceta Prešerna, ki so poznani večini slovenskih govorcev. Pozna in uporablja jo $67,4 \%$, pozna, a ne uporablja $29,7 \%$, dva anketiranca pa sta dodala pravopisno varianto $\mathrm{z}$ malo začetnico.

\subsection{Dianormativna razlika}

Razlika med frazeološkima enotama se lahko kaže v primernosti z vidika socialne norme v navezavi na knjižni jezik. Primer take razlike sta sinonima Gliha vkup štriha in Vrana $k$ vrane sadá. V slovenskem primeru so vse leksikalne sestavine neknjižne. Domnevamo, da bi bilo zanimivo proučiti medsebojni vpliv diamedialne in dianormativne razlike, saj se neknjižne enote najbrž v pisnih virih pojavljajo manj v primerjavi z govorom. Tudi to razliko bo možno zaznati $\mathrm{v}$ podatkovni bazi vprašalnika med navedenimi variantami.

\subsection{Diatehnična razlika}

Ekvivalentnost primerjanih frazeoloških enot lahko presojamo tudi z vidika njihovega uveljavljanja $\mathrm{v}$ splošnem ali strokovnem jeziku. Za diatehnično razliko bi lahko zaradi močne vpetosti v športni žargon šlo pri enoti Žoga je okrogla v odnosu do slovaškega nadpomenskega pregovora Štastie je vrtkavé (Sreča je opoteča). Idionimični izraz Lopta je okruhlá se prav tako razlikuje od slovenske ustreznice. To razliko bi lahko potrdili šele $\mathrm{z}$ raziskavo $\mathrm{v}$ jezikovnih korpusih, ki omogočajo vpogled v sobesedilo. Najbrž se taka razlika odraža na diafrekvenčni razliki podobno kot diatekstovna. 


\section{Zaključki}

Ogledali smo si distribucijo tipov ekvivalentnosti po slovenskem paremiološkem minimumu v razmerju do slovaščine. Enajstim izmed petdesetih najbolj poznanih enot iz njega ustrezajo enote, ki se nahajajo v slovaškem minimumu petdesetih najbolj poznanih. Poleg njih smo še šestindvajsetim enotam našli slovaške ustreznice $\mathrm{v}$ naboru petstotih najbolj poznanih, ki jih je $\mathrm{z}$ demografsko raziskavo zamejil Ďurčo (2002: 52-53). Le trinajstim slovenskim enotam smo morali ustreznice poiskati izven tega seznama. O bližini slovaške in slovenske paremiologije priča 39 od 50 slovenskih enot, ki imajo vsaj eno enako motivirano ustreznico. Ostalim smo našli ustreznice, ki so motivirane drugače, primera idiosinkrazije pa ni bilo. Kot kažejo dosedanje raziskave, je stopnja idiosinkrazije med slovenščino in slovaščino nizka v primerjavi $\mathrm{z}$ ostalimi zastopanimi tipi. To stanje bi bilo zanimivo primerjati $\mathrm{z}$ raziskavami med slovenščino in drugimi slovanskimi jeziki ter jeziki iz drugih skupin.

Poleg razvrstitve po tipologiji smo upoštevali še diasistemski vidik. Vsaj pri desetih enotah iz slovenskega minimuma nam zaenkrat ni uspelo najti slovaške ustreznice, ki se ne bi močno razlikovala po suprasemantičnih lastnostih. Vprašanje diafrekvenčne razlike je zelo pomembno za dvojezično frazeografijo in frazeodidaktiko. Diafrekvenčna razlika je močno povezana z diahrono razliko. Obenem je pomembno vprašanje, na osnovi česa ugotavljamo diafrekvenčno razliko. Zaenkrat se lahko zanesemo le na dovolj obsežne pisne korpuse. Morda bodo nekoč tudi korpusi s posnetki govora služili temu namenu. Ugotovili smo še povezave diafrekvenčne razlike z diatekstovno, diaintegrativno, diamedialno in drugimi. Poleg omenjenih povezav smo izpostavili še možnost povezav med diamedialno in dianormativno ter med diamedialno in diastratično razliko.

Za prihodnje raziskave je zanimivo vprašanje, kdaj ter v kolikšni meri gre za medsebojno vplivanje diasistemskih dejavnikov in kdaj ter v kolikšni meri za njihovo soobstajanje brez izrazitega medsebojnega vplivanja. Pri večini vprašanj v zvezi s suprasemantiko si bomo v prihodnosti lahko pomagali $\mathrm{s}$ podatkovno bazo vseslovenskega demografskega vprašalnika. Pri tem si lahko pomagamo tudi s stanjem v jezikovnih korpusih, vsekakor pa to ne more zadoščati. Potrebne bodo specifične raziskave, na primer pri ugotavljanju diastratičnih razlik.

VIRI

Bisernice iz belokranjskega narodnega zaklada: <http://sl.wikisource.org/wiki/Bisernice_iz_belokranjskega_narodnega_zaklada_I>. (Dostop 2. 9. 2013.)

Etbin BOJC, 1987: Pregovori in reki na Slovenskem. Ljubljana: Državna založba Slovenije.

Korpus slovenskega jezika FidaPLUS: <http://www.fidaplus.net>. (Dostop 2. 9. 2013.) 
Paremiologická databáza: <https://data.juls.savba.sk/paremiografia>. (Dostop 2. 9. 2013.)

Josip PAVLICA, 1960: Frazeološki slovar v petih jezikih. Ljubljana: Državna založba Slovenije.

Slovar slovenskega knjižnega jezika $\mathrm{SSKJ}$ : <http://bos.zrc-sazu.si/sskj.html>. (Dostop 2. 9. 2013.)

Slovenský národný korpus - prim-6.0-public-all. Bratislava: Jazykovedný ústav L'. Štúra $S A V:<\mathrm{http}: / /$ korpus.juls.savba.sk>. (Dostop 2. 9. 2013.)

Sprichwort-Plattform: <http://www.sprichwort-plattform.org>. (Dostop 2. 9. 2013.)

Adolf Petr ZÁTURECKÝ, 1896: Slovenská přisloví, pořekadlá a úsloví. Praga: Alois Wiesner.

\section{LITERATURA}

František ČERMÁK, 1983: Lexikálni opozice, paradigma a systém. Slovo a slovesnost 44, 207-219.

- -, 2003: Paremiological Minimum of Czech: The Corpus Evidence. Flut von Texten - Vielvalt der Kulturen. Ascona 2001 zur Methodologie und Kulturspezifik der Phraseologie. Ur. Harald Burger, Annelies Häcki Buhofer, Gertrud Greciano. Hohengehren: Schneider Verlag. 15-31.

Juraj DOLNÍK, 1987: Logické princípy organizácie slovnej zásoby. Slovenská reč 52/3, 129-138.

Peter ĎURČO, 2001: Bekanntheit, Häufigkeit und lexikographische Erfassung von Sprichwörtern. Zu parömiologischen Minima für DaF. Phraseologiae Amor. Aspekte europäischer Phraseologie. Ur. Annelies Häcki Buhofer, Harald Burger, Laurant Gautier. Hohengehren: Schneider Verlag. 99-106.

- -, 2002: K výskumu súčasnej živej slovenskej paremiológie. Prednášky XXXVIII. letnej školy slovenského jazyka a kultúry. Ur. Jozef Mlacek. Bratislava: Stimul. (Studia Academica Slovaca, 31). 51-60.

--, 2002a: Unterschiede in der (Un)kenntnis von Sprichwörtern in verschiedenen Lebensaltern. Spracherwerb und Lebensalter. Ur. Annelies Häcki Buhofer. Tübingen in Basel: Francke Verlag. 293-304.

--, 2006: Methoden der Sprichwortanalysen oder Auf dem Weg zum Sprichwörteroptimum. Phraseology in Motion. Methoden und Kritik. Akten der Internationalen Tagung zur Phraseologie - Basel, 2004. Ur. Annelies Häcki Buhofer, Harald Burger. Hohengehren: Schneider Verlag. (Phraseologie und Parömiologie Band 19). 3-20.

- -, 2012: Diasystematische Differenzen von Sprichwörtern aus der Sicht der kontrastiven Parömiologie. Sprichwörter multilingual. Theoretische, empirische und angewandte Aspekte der modernen Parömiologie. Ur. Kathrin Steyer. Tübingen: Narr Verlag. (Studien zur deutschen Sprache 60). 357-377. 
- -, 2012a: Typológia ekvivalentnosti vo frazeológii. Na príklade ruských, slovenských a nemeckých parémií. Aspekty lexikálnej sémantiky - gramatika - štylistika (pragmatika). Ur. Klára Buzássyová, Bronislava Chocholová, Nicol Janočková. Bratislava: Veda. (Slovo v slovníku). 91-102.

Peter ĎURČO, Kathrin STEYER, v tisku: Ein korpusbasiertes Beschreibungsmodell für die elektronische Sprichwortlexikografie. Tous les chemins mènent à Paris Diderot. Actes $d u$ Colloque international de Parémiologie, Université Paris Diderot 29 juin-2 juillet 2011. Ur. Natalie Übler, Jean-Michel Benayoun, Jean-Philippe Zouogbo. Hohengehren: Schneider Verlag. <http://www.owid.de/extras/sprw/SW_ Modell_steyer_durco.pdf.> (Dostop 2. 9. 2013.)

Peter GRZYBEK, 2008: Fundamentals of Slovenian paremiology. Traditiones 37/1, $23-46$.

Peter GRZYBEK, Rupprecht BAUR, Christoph CHLOSTA, 1996: Das Projekt Sprichwörter-Minima im Deutschen und Kroatischen: What is worth doing - do it well! Muttersprache 2, 162-179.

Peter GRYZBEK, Christoph CHLOSTA, 1995: Empirical and Folkloristic Paremiology: Two to Quarrel of to Tango? Proverbium 12, 67-85.

- -, 2008: Some Essentials on the Popularity of (American) Proverbs. Festschrift on the Occasion of Wolfgang Mieder's 65th Birthday. Ur. Kevin McKenna. Burlington: University of Vermont. 95-110.

Erla HALLSTEINSDÓTIRR, Ken FARØ, 2010: Interlinguale Phraseologie. Yearbook of Phraseology 1. Ur. Koenraad Kuiper. 125-158.

Erika KRŽIŠNIK, 1988: Frazeološko gradivo v Slovarju slovenskega knjižnega jezika. Slava 2, 143-162.

Jarmo KORHONEN, 2007: Phraseme im Sprachgebrauch und in der Übersetzung. Phraseology. An International Handbook of Contemporary Resarch. Ur. Harald Burger, Dmitrij Dobrovoljskij, Peter Kühn, Neal Norrick. Berlin, New York: Walter de Gruyter. 574-589.

Nataša LOGAR, 2001: Kvalifikator ekspr. v Slovarju slovenskega knjižnega jezika na ravni frazeologije. Jezik in slovstvo 46/4, 137-148.

Marija MAKAROVIČ, 1975: Pregovori, življenjske resnice. Ljubljana: Kmečki glas.

Matej METERC, v tisku: Online questionnaire providing information on most well-known and well-understood proverbs in Slovene language. (Europhras; Frazeologija in kultura. Maribor, 27.-31. 8. 2012). Maribor: Filozofska fakulteta.

- -, 2012: Transformacije frazeoloških enot in prepoznavanje transformacij v drugem slovanskem jeziku med slovenskimi in slovaškimi govorci. Individualna in kolektivna dvojezičnost. Ur. Petra Stankovska, Maria Wtorkowska, Jozef Pallay. Ljubljana: Znanstvena založba Filozofske fakultete Univerze v Ljubljani. (Slavica Slovenica). 323-329.

- -, 2013: Antonimija enako motiviranih paremioloških enot (primeri iz slovenščine in slovaščine). Slavistična revija 61/2, 361-376.

Wolfgang MIEDER, 1997: Modern Paremiology in Retrospect and Prospect. Paremia 6, 399-416. 
--, 2004: Proverbs. A handbook. Westport, Connecticut: Greenwood Press.

Jozef MLACEK, Peter ĎURČO, 1995: Frazeologická terminológia. Bratislava: Stimul.

Valerij MOKIJENKO, 2012: Russisches parömiologisches Minimum: Theorie oder Praxis? Sprichwörter multilingual. Theoretische, empirische und angewandte Aspekte der modernen Parömiologie. Ur. Kathrin Steyer. Tübingen: Narr. 79-99.

Grigorij PERMJAKOV, 1988: Osnovy strukturnoj paremiologii. Moskva: Nauka.

--, 1989: On the Question of a Russian Paremiological Minimum. Proverbium 6, 91-102.

Stane SUHADOLNIK, 1961: Josip Pavlica: Frazeološki slovar v petih jezikih. Jezik in slovstvo 6/6, 200-205.

\section{EMPIRICAL PAREMIOLOGICAL STUDIES ON TYPES OF EQUIVALENCY AND SUPRASEMANTIC DIFFERENCES IN SLOVENE AND SLOVAK}

The article uses the typology of equivalency based on the formal and semantic relations (relation of identity, of privative or equipollent opposition and the relation of disjunction) as it was developed in phraseology by Durčo. The article examines the paremiological minimum that consists of fifty proverbs marked as the most well-known by Slovene native speakers in a demographic survey conducted by Meterc in 2012 in the form of a full-text presentation (FTP). The first part of the article attempts to establish which types of equivalency occur in the relation between the Slovene paremiological minimum and the Slovak minimum represented by Durčo. This allows the authors to show the distribution of the equivalency types between the two Slavic languages along with the data on knowledge of the proverb. Not all the equivalents are present among the fifty and not even among the five hundred most well-known Slovak units. For this reason the Slovak units from secondary sources also had to be included. In the second part of the article, empirically gleaned data on proverb familiarity and data on proverb frequency based on the situation in Slovene and Slovak language corpora are used to shed light on suprasemantic differences. The authors are concerned with the diachronic, diatopic, diaintegrative, diamedial, diastratic, diatextual, diafrequent, diaphasic, diaevaluative, dianormative and diatechnic aspects of phraseological equivalency. The article mentions the possible causal connections between the types of suprasemantic differences as well as speculates on where further research is needed in order to prove them. 